\title{
Review of birth defects in a community hospital over a ten-year period
}

\begin{abstract}
Approximately 1 in 33 babies born in the United States (U.S.) with birth defects accounts for $20-30 \%$ of all deaths among neonates. In New York State, 1 out of every 20 children is born with a major malformation. ${ }^{1}$ Birth defects are responsible for the majority of the morbidity and mortality rates, irrespective of weight and gestational age. They are detected during the antenatal period; intrapartum; and soon after birth, during the perinatal period. Causes of most birth defects are unknown. We did a retrospective chart review over a 10 year period identifying various anomalies, classifying them as major or minor anomalies, and looking for any clustering of defects in an urban community hospital.
\end{abstract}

Keywords: Congenital anomalies, Urban population, Perinatal period, Birth defects
Volume 5 Issue 2 - 2016

\author{
Michelle Vaz, Evelyn Erickson, Benamanhalli \\ Rajegowda \\ Department of Pediatrics, Lincoln Medical Center in Affiliation \\ with Cornell University, USA
}

Correspondence: Benamanhalli Rajegowda, Department of Pediatrics Lincoln Medical Center, 234 E I49th St, Bronx, NY, USA, 1045I,Email benamanhalli.rajegowda@nychhc.org

Received: June 24, 2016 | Published: August 31, 2016

\section{Introduction}

An estimated 276,000 babies die within four weeks of birth every year worldwide from congenital anomalies. ${ }^{2}$ The most common severe congenital anomalies are heart defects, neural tube defects and Down Syndrome. Although congenital anomalies may be genetic, infectious, nutritional or environmental in origin, most often it is difficult to identify the exact cause. ${ }^{2}$ In 2004 , hospital costs in the U.S. for birth defects totaled $\$ 2.6$ billion dollars and accounted for more than 139,000 hospitalizations. ${ }^{3}$ They are classified as major and minor defects, with major accounting for $3 \%$ incidence rate and minor having a varied incidence of 5-10\%. Major birth defects are conditions present at birth that cause structural changes in one or more parts of the body. They can have a serious, adverse effect on health, development, or functional ability. Minor birth defects are generally considered of limited social or medical significance. While minor anomalies do not greatly affect the child, they can be related to major anomalies or be indications of certain syndromes. Effects of birth defects can range from mild to severe and can result in debilitating illness, long-term disability or death. It is not only a leading cause of fetal loss, but also contributes significantly to preterm birth, childhood and adult morbidity, along with considerable repercussion on the mothers and their families.

The New York Congenital Malformation Registry primarily identifies changes in malformation rates over time that may signal a change in women's health or environmental conditions and other factors; identifies geographical areas with consistently high rates; provides summaries and tables to the public, health providers, and local health departments; efficiently investigates reports of unusual numbers of malformations ensuring that families of children identified in the Registry find available resources so that each child can maximize his or her development; and lastly identifies families of children with specific malformations who may be invited to participate in research studies. $^{3}$

Our institution is located in an urban area serving predominantly a minority and immigrant population of low socioeconomic status. They have multiple social, behavioral, medical, and educational issues. The population is comprised of $70 \%$ Hispanic, $25 \%$ African-American and the remainder from other nationalities, with a median income of $\$ 13,776 .{ }^{4}$ Many pregnant women do not have continuity of medical care and some have limited or no prenatal care. A lot of them have no prior antenatal scans, and anomalies are detected at birth or after birth. Mothers identified with fetal anomalies in anatomy scans are either referred to tertiary centers for delivery or deliver at our hospital with the consulting teams having been informed. The objectives of our study were to primarily review the type of birth defects that occurred over a 10 year period; and secondarily to detect any clustering of these defects in an urban community hospital.

\section{Methods}

This study was approved by the institutional review board (IRB) committee of Lincoln Medical Center. Prospective maternal and infant data were collected by the senior author daily and were analyzed retrospectively by the authors by reviewing detailed documentation through online electronic medical records along with paper charts and documents maintained in the office over the previous years. Data were collected from January 1, 2003 through December 31, 2012 by reviewing all infants born with documented congenital anomalies, single or multiple; and major or minor birth defects during the perinatal period.

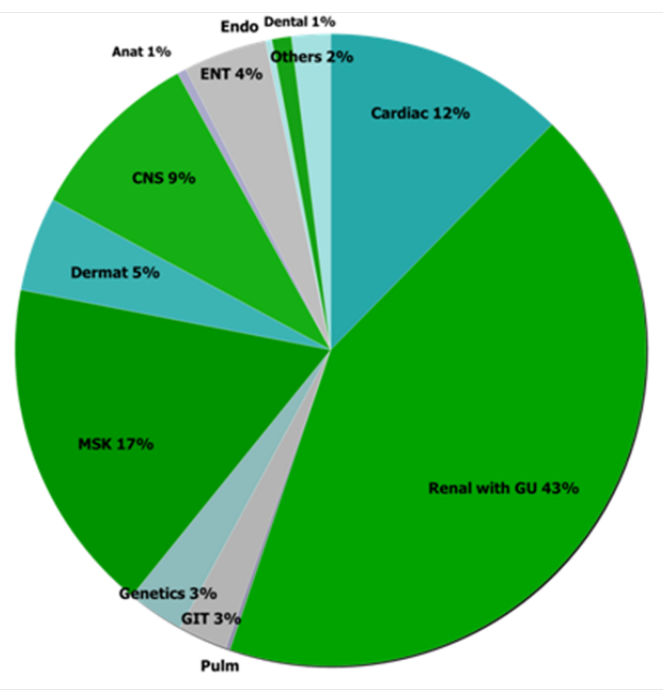

Figure I System Based Anomalies. 


\section{Results}

We analyzed the incidence of congenital anomalies based on race, birth weight, and antenatal detection, taking into account the systembased occurrence for any clustering of defects. During the study period, there were 24,203 live births in our institution. Of these, 2,156 infants were identified with congenital anomalies with a hospital incidence of $8.90 \%$. This included those with multiple anomalies. There were a total of 2,348 anomalies detected, including single and multiple non-syndrome, unrelated anomalies. Of those, 398 (16.9\%) were classified as major anomalies, whereas 1,950 out of 2,348 (83.04\%) were identified as minor anomalies (Table 1). Out of 398, 145 major anomalies were detected prenatally $(36.43 \%)$; renal and chromosomal anomalies were the most common birth defects detected antenatally, whereas structural anomalies were identified postnatally (Figure 1).

\section{Discussion}

The pattern and prevalence of congenital anomalies may vary over time or with geographical location, reflecting a complex interaction of known and unknown genetic and environmental factors including socio-cultural, racial and ethnic variables. ${ }^{5}$ The majority of the defects were noted within the Hispanic population (73.38\%), which aligned with our population distribution (70\% Hispanic); hence it wasn't statistically significant (Table 2). The main defect was renal, and most were detected prenatally, which shows the ease of the sonographer with these defects in pregnant women. The majority of the major anomalies were cardiac, and mostly detected during the postnatal period. Surveillance for cardiac defects must be increased, particularly in high risk groups. The entire dental and most of the MSK anomalies were detected postnatally, as these are minute and very difficult to detect on fetal sonograms. Most of the anomalies, either cardiac or renal, were seen in infants $>2.5 \mathrm{~kg}$, and not so often in low-birth weight (LBW) infants (Table 3). This is markedly different from studies based in Asia, including Turkey and India, where predominant anomalies were seen in LBW babies. ${ }^{6,7}$ In preliminary analysis of chart review, most of the renal defects were resolved by 5 years of age without any major intervention. A comprehensive list is yet to be put together. Also, no significant increase or clustering was noted in our population set, so no initial assessment on the role of environmental factors towards these major defects were conducted. An important limitation of our study was that we could not include cases of abortions and stillborn births, because often the abnormalities are not obvious or visible externally. In those cases, a pathological autopsy is warranted and parental consent is not available for pathological autopsies. Secondly, minor defects may have been missed on data collection with uneven reporting. Finally, parity of the mothers was not taken into consideration, though some studies in developing countries have shown an increase incidence in multiparous women. ${ }^{8,9}$

Table I Incidence Based on Race, Birth Weight and Method of Detection

\begin{tabular}{|c|c|c|c|c|c|c|c|}
\hline \multirow{2}{*}{ Anomalies } & \multicolumn{3}{|l|}{ Ethnicity } & \multicolumn{2}{|c|}{ Low Birth Weight (LBW) } & \multicolumn{2}{|c|}{ Antenatal Detection } \\
\hline & Hispanics & African Americans & Asians \& Others & $<2.5 \mathrm{~kg}$ & $>2.5 \mathrm{~kg}$ & Prenatal & Postnatal \\
\hline Major-16.90\% & $279-11.80 \%$ & $104-4.50 \%$ & $15-0.60 \%$ & $96-4.00 \%$ & $302-12.90 \%$ & $145-6.20 \%$ & $253-10.70 \%$ \\
\hline Minor-83.00\% & $|444-6| .50 \%$ & $457-19.50 \%$ & $49-2.00 \%$ & $148-6.30 \%$ & $1802-6.70 \%$ & $962-41 \%$ & $988-42 \%$ \\
\hline
\end{tabular}

Table 2 System and Race Based Anomalies

\begin{tabular}{|c|c|c|c|c|c|c|}
\hline Systems & Major & Minor & Total & Hispanics & African Americans & Others \\
\hline Cardiac & 104 & 188 & 292 & $193(66.00 \%)$ & $85(29.10 \%)$ & $14(4.79 \%)$ \\
\hline Renal & 39 & 702 & $74 I$ & $573(77.30 \%)$ & 148 (| $19.90 \%)$ & $20(2.70 \%)$ \\
\hline Genitourinary & 28 & 235 & 263 & $210(79.80 \%)$ & $49(18.60 \%)$ & $4(0.15 \%)$ \\
\hline Pulmonary & $\mathrm{I}$ & 4 & 5 & $3(60.00 \%)$ & $2(40.00 \%)$ & $0(0 \%)$ \\
\hline Gastrointestinal & 17 & 43 & 60 & $35(58.30 \%)$ & $24(40.00 \%)$ & $\mathrm{I}(\mathrm{I} .60 \%)$ \\
\hline Genetics & 57 & 12 & 69 & $4 I(59.40 \%)$ & $22(31.80 \%)$ & $6(8.69 \%)$ \\
\hline Musculoskeletal & 67 & 339 & 406 & $293(72.10 \%)$ & $105(25.80 \%)$ & $8(1.97 \%)$ \\
\hline Dermatology & 0 & 114 & 114 & 78 (68.40\%) & $35(30.70 \%)$ & I $(0.80 \%)$ \\
\hline Central Nervous System (CNS) & 50 & 164 & 214 & $159(74.20 \%)$ & $50(23.30 \%)$ & $5(2.33 \%)$ \\
\hline Anatomical & 0 & II & II & $5(45.40 \%)$ & $5(45.40 \%)$ & I (9.00\%) \\
\hline Ear, Nose and Throat (ENT) & 9 & 92 & 101 & $74(73.20 \%)$ & $25(24.70 \%)$ & $2(1.98 \%)$ \\
\hline Endocrine & 2 & 6 & 8 & $7(87.50 \%)$ & I (I2.50\%) & $0(0 \%)$ \\
\hline Dental & 0 & 23 & 23 & $18(78.20 \%)$ & $5(21.70 \%)$ & $0(0 \%)$ \\
\hline Other & 24 & 17 & 41 & 34 (82.90\%) & $5(12.20 \%)$ & $2(4.80 \%)$ \\
\hline Total & 398 & 1950 & 2348 & $1723(73.38 \%)$ & $56 \mathrm{I}(23.89 \%)$ & $64(2.70 \%)$ \\
\hline
\end{tabular}

Table 3 Weight (Wt) Based and Detection Based Analysis

\begin{tabular}{|c|c|c|c|c|c|}
\hline Systems & $W t<2.5 \mathrm{~kg}$ & Wt>2.5kg & Total & Prenatal & Postnatal \\
\hline Cardiac & 35 (1 $1.90 \%)$ & $257(88.00 \%)$ & 292 & II 3 (39.60\%) & 179 (6I. $.40 \%)$ \\
\hline Renal & $60(8.09 \%)$ & 681 (91.90\%) & 741 & 735 (99.20\%) & $6(0.80 \%)$ \\
\hline Genitourinary & $24(9.12 \%)$ & $239(90.80 \%)$ & 263 & $4(0.60 \%)$ & $259(98.40 \%)$ \\
\hline Pulmonary & I (20.00\%) & $4(80.00 \%)$ & 5 & $4(80.00 \%)$ & I $(20.00 \%)$ \\
\hline Gastrointestinal & $12(20.00 \%)$ & $48(80.00 \%)$ & 60 & $34(56.60 \%)$ & $26(43.30 \%)$ \\
\hline Genetics & 31 (44.90\%) & 38 (55.07\%) & 69 & 46 (66.60\%) & 23 (33.30\%) \\
\hline MSK* & 32 (7.80\%) & 374 (92.10\%) & 406 & $2(0.50 \%)$ & 404 (99.50\%) \\
\hline Dermatology & $6(5.20 \%)$ & $108(94.70 \%)$ & 114 & I $(0.90 \%)$ & $113(99.10 \%)$ \\
\hline CNS* & $22(10.30 \%)$ & 192 (89.70\%) & 214 & $150(70.00 \%)$ & $64(30.00 \%)$ \\
\hline Anatomical & I $(9.10 \%)$ & $10(90.90 \%)$ & 11 & $0(0 \%)$ & II (I00.00\%) \\
\hline ENT* & $3(3.00 \%)$ & 98 (97.00\%) & 101 & I (I.00\%) & 100 (99.00\%) \\
\hline Endocrine & I (I2.50) & 7 (87.50\%) & 8 & $3(37.50 \%)$ & $5(62.50 \%)$ \\
\hline Dental & $8(34.70 \%)$ & $15(65.20 \%)$ & 23 & $0(0 \%)$ & $23(100.00 \%)$ \\
\hline Others & $8(19.50 \%)$ & $33(80.50 \%)$ & 41 & $14(34.20 \%)$ & $27(65.80 \%)$ \\
\hline
\end{tabular}

*MSK: Musculoskeletal; CNS: Central Nervous System; ENT: Ear, Nose and Throat 


\section{Conclusion}

The antenatal detected defects were chromosomal and major structural anomalies; and were detected using prenatal testing such as amniocentesis and imaging studies. Despite antenatal screening, testing, counseling and termination of pregnancy (where applicable), major and minor birth defects continue to occur. A thorough review of maternal history, maternal labs and examination of the infant at birth will detect most, if not all, birth defects. The most common deformity detected was of the genito-urinary tract including renal, though we did not see any clustering. Many states in the U.S. initiated a program to screen newborns for roughly 46 inborn errors of metabolism (IEM). Early intervention and management will help prevent morbidity and mortality and allay fear and apprehension for parents and families. The recent federal policy on monitoring all infants by pulse oximetry prior to discharge, implemented in July 2013, helps to detect ductal dependent Critical Congenital Heart Defects (CCHD) and identify those missed by clinical examination, necessitating it as an additional neonatal screening tool.

\section{Acknowledgments}

None.

\section{Conflicts of interest}

None.

\section{References}

1. Center for Disease Control (CDC). Update on Overall Prevalence of Major Birth Defects — Atlanta, Georgia, 1978-2005. 200857(01):15.
2. World Health Organization (WHO) (2015) Congenital anomalies. Fact sheet $\mathrm{N}^{\circ} 370$.

3. Congenital Malformation Registry.

4. Nithi Fernandes, Sonali Malhotra, Evelyn Erickson, et al. Identification of Perinatal Hepatitis B Seropositive Status and Chemoprophylaxis to Prevent Vertical Transmission in a South Bronx Population. e-Journal of Neonatology Research. 2013;3(3): 59-64.

5. Birch MR, Grayson N, Sullivan EA. Recommendations for development of a new Australian birth anomalies system: A review of the congenital malformations and birth defects data collection. Birth Anomalies Series No. 1. Cat. No. PER 23. AIHW National Perinatal Statistics Unit, Sydney, USA. 2004.

6. Khatemi F, Mamoori GA. Survey of congenital major malformations in 10/000 newborns. Iran J Pediatr. 2005;15:315-320.

7. Tomatir AG, Demirhan H, Sorkun HC, et al. Major congenital anomalies: A five-year retrospective regional study in Turkey. Genet Mol Res. 2009;8(1):19-27.

8. Panjvani Zehra, Edgar Torres, Rhina Castillo, et al. Mortality Trends and Cause of Death among Infants Weighing $2.5 \mathrm{~kg}$ or more at Birth in an Inner City Hospital over an 18 year Period. The e-Journal of Perinatology Research. 2012;2(4):190-194.

9. Sarkar S, Patra C, Dasgupta MK, et al. Prevalence of Congenital Anomalies in Neonates and Associated Risk Factors in a Tertiary Care Hospital in Eastern India. J Clin Neonatol. 2013;2(3):131-134. 